\title{
Association of exposure to hydrocarbon air pollution with the incidence of atopic dermatitis in children
}

\author{
Chieh Wang ${ }^{1 \dagger}$, Chang-Ching Wei ${ }^{2,3+}$, Lei Wan ${ }^{4}$, Cheng-Li Lin ${ }^{5,6}$ and Jeng-Dau Tsai, ${ }^{7,8^{*}}$
}

\begin{abstract}
Background: There is growing evidence suggesting that air pollution may act as an important environmental risk factor in the development and aggravation of childhood atopic dermatitis (AD).

Methods: We collected data from the Taiwan National Health Insurance (NHI) research database and linked the data to the Taiwan Air Quality-Monitoring Database. From January 1, 2000 to December 31, 2012; children aged below 18 years were selected from the database and followed longitudinally until the diagnosis of $A D$, withdrawal from the NHI, or December 31, 2012. Children with missing data or those diagnosed with AD before enrolment in this study were excluded. We measured the incidence rate and hazard ratios (HRs) for AD and stratified them by quartiles (Q1-Q4) of air pollutant concentration. Multivariable Cox proportional hazards models were also applied by adjusting for age, sex, monthly income, and level of urbanization.
\end{abstract}

Results: When compared with the concentrations of pollutants in the Q1 quartile, the adjusted HR for AD increased with an increase in the exposure concentrations of total hydrocarbons (THCs), non-methane hydrocarbons (NMHCs), and methane $\left(\mathrm{CH}_{4}\right)$ from 1.65 (95\% confidence interval [Cl]: 1.47-1.84) to 10.6 (95\% Cl: 5.857.07), from 1.14 (95\% Cl: $1.06-1.24)$ to 2.47 (95\% Cl: $2.29-2.66)$, and from 1.70 (95\% Cl: $1.52-1.89$ ) to 11.9 (95\% Cl: 10.8-13.1), respectively. Patients exposed to higher levels of $\mathrm{THCs}$, $\mathrm{NMHCs}$, and $\mathrm{CH}_{4}$ exhibited greater incidence rates of childhood $A D$.

Conclusions: The present study demonstrated that exposure to higher concentrations of THCs, $\mathrm{NMHCs}$, and $\mathrm{CH}_{4}$ were associated with an increased risk of childhood AD.

Keywords: Air pollution, Atopic dermatitis, Children, Cohort study, Hydrocarbons, Non-methane hydrocarbon, Total hydrocarbon, Methane, Environmental pollutants

\section{Background}

Atopic dermatitis (AD) is a common chronic relapsing inflammatory skin disease associated with intense itching and recurrent eczematous lesions [1]. Hanifin-Rajka major diagnostic criteria including pruritus, typical

\footnotetext{
* Correspondence: fernand.tsai@msa.hinet.net; d5522@mail.cmuh.org.tw ${ }^{+}$Chieh Wang and Chang-Ching Wei contributed equally to this work. ${ }^{7}$ School of Medicine, Chung Shan Medical University, Taichung, Taiwan ${ }^{8}$ Department of Pediatrics, Chung Shan Medical University Hospital, Taichung, Taiwan

Full list of author information is available at the end of the article
}

morphology, chronic or chronically relapsing dermatitis, and personal or family history of atopy have been used most frequently to diagnose $\mathrm{AD}$ in Taiwan [2]. In a process referred to as the "atopic march," food allergy and AD are usually an early sign of other subsequent allergic disorders $[3,4]$. Up to $80 \%$ of the children with $\mathrm{AD}$ eventually develop allergic rhinitis or asthma later in their childhood [5]. AD begins most commonly in the early childhood. Approximately $15-30 \%$ of the children and $10 \%$ of the adults are affected worldwide $[6,7]$. In

(c) The Author(s). 2021 Open Access This article is licensed under a Creative Commons Attribution 4.0 International License, which permits use, sharing, adaptation, distribution and reproduction in any medium or format, as long as you give appropriate credit to the original author(s) and the source, provide a link to the Creative Commons licence, and indicate if changes were made. The images or other third party material in this article are included in the article's Creative Commons licence, unless indicated otherwise in a credit line to the material. If material is not included in the article's Creative Commons licence and your intended use is not permitted by statutory regulation or exceeds the permitted use, you will need to obtain permission directly from the copyright holder. To view a copy of this licence, visit http://creativecommons.org/licenses/by/4.0/ The Creative Commons Public Domain Dedication waiver (http://creativecommons.org/publicdomain/zero/1.0/) applies to the data made available in this article, unless otherwise stated in a credit line to the data. 
approximately $80 \%$ of the cases, childhood AD did not persist beyond 8 years of age and in less than $5 \%$ of the cases, it persisted into adulthood. Particularly, prolonged persistence of $\mathrm{AD}$ (more than 10 years) was associated with greater severity of the disease [8]. AD obviously influences patients' quality of life and has financial implications. Itching and scratching are the two main symptoms that affect the quality of life in childhood AD. These symptoms affect the quality of sleep, thus requiring a treatment regime, affect the ability to participate in sporting activities, and result in social embarrassment [9]. The 2006 report from the American Academy of Dermatology, the most comprehensive contemporary research on the economic impact of $\mathrm{AD}$, revealed that the total annual burden of $\mathrm{AD}$ was $\$ 4.228$ billion. $\mathrm{AD}$ was associated with the fifth-highest overall treatment cost among all skin diseases in the US, placing a tremendous financial burden on the society [10]. Hence, it is critical to identify and control the risk factors in susceptible subjects for successful treatment and prevention of childhood AD.

Over the past 30 years, the worldwide prevalence of AD has increased considerably, particularly in industrialized countries [6]. Although both genetic and environmental factors are involved in the etiology of $\mathrm{AD}$, the recent increase in the prevalence of is mainly attributed to environmental factors [11]. There is growing evidence suggesting that air pollution may act as an important environmental risk factor for the development and aggravation of childhood $\mathrm{AD}$ [12-15]. A variety of air pollutants such as particulate matter (PM); nitrogen oxide compounds $\left(\mathrm{NO}_{\mathrm{x}}\right)$; environmental tobacco smoke (ETS); traffic-related air pollution (TRAP) caused by pollutants such as $\mathrm{PM}, \mathrm{NO}, \mathrm{NO}_{2}, \mathrm{SO}_{2}, \mathrm{CO}, \mathrm{CO}_{2}, \mathrm{O}_{3}$; and volatile organic compounds (VOCs) have been mentioned as risk factors for the development or aggravation of AD [11]. Skin barrier dysfunction is considered the initial step in the development of AD. The skin barrier plays pivotal roles in immune surveillance and homeostasis and in preventing the penetration of irritants and allergens $[6,16,17]$. Air pollutants may induce oxidative stress in the skin, leading to skin barrier dysfunction or immune dysregulation $[18,19]$. TRAP, especially $\mathrm{O}_{3}$, has been observed to alter the resident skin flora and cause predisposition to $S$. aureus colonization [18]. Other dust particles and diesel exhaust particulates have also been demonstrated to exert toxicological effects on human skin [19]. Further research is needed to determine the mechanism behind the role of air pollutants in AD.

Although several studies support the development or aggravation of childhood $\mathrm{AD}$ due to air pollutants, current evidence regarding the skin aspects of air pollution remains relatively scarce in contrast to that regarding airway diseases such as asthma [20]. Moreover, previous studies have limitations such as inaccurate study design and assessment and the presence of confounding variables such as obesity, genetics, and comorbidities. For example, several studies have considered a mixture of substances including ETS, VOCs, and $\mathrm{NO}_{\mathrm{x}}$, representing a combined impact on human health. Selection bias was also observed due to potential misclassification in some cross-sectional studies, since the diagnosis of $\mathrm{AD}$ was not confirmed by a physician and was based simply on reports from the patients or their parents [11].

In the present study, we focused on the association between hydrocarbons and the development of childhood AD. Total hydrocarbons (THCs), which are organic chemical compounds consisting of non-methane hydrocarbons (NMHCs) and methane $\left(\mathrm{CH}_{4}\right)$, are responsible for approximately $85 \%$ of the global energy consumption due to rapid industrialization and urbanization. It is unclear whether air pollutants released during combustion of hydrocarbons, particularly $\mathrm{CH}_{4}$, affect the body's largest organ, the skin. Hence, we conducted this nationwide retrospective study using real-world data in Taiwan to evaluate the effect of exposure to these air pollutants on the risk of $\mathrm{AD}$ in children.

\section{Methods}

\section{Data source}

We conducted a retrospective cohort study using the Children's File, a representative database including data from half of all children randomly selected from the registry of beneficiaries of the Taiwan National Health Insurance (NHI) Research Database (NHIRD) for the year 2000. The NHIRD was established in 1995 and covers more than $99 \%$ of the total population in Taiwan [21]. It contains all medical records including deidentified demographic information such as sex, birth dates, occupation of the beneficiaries, and place of residence and clinical information such as diagnostic codes based on the International Classification of Disease, 9th Revision, Clinical Modification [ICD-9-CM] [22]; health management; and treatment. Since all the research data were anonymized and encrypted to protect the individuals' privacy, the requirement for consent was waived for this study. The study was approved by the Institute Review Board of China Medical University Hospital (CRREC-103-048) and the study procedures were in accordance with the principles of the Declaration of Helsinki.

\section{Study population, outcome of interest, endpoints, and confounding factors}

From January 1, 2000 to December 31, 2012; We obtained data from children aged below 18 years. Candidates with missing data or those diagnosed with $\mathrm{AD}$ 
before enrolment in this study were excluded. The diagnosis of $\mathrm{AD}$ by a physician in Taiwan relies on clinical features listed in the Hanifin and Rajka diagnostic criteria and the American Academy of Dermatology Consensus Criteria [1, 2]. The $\mathrm{AD}$ diagnosis guideline established by the Taiwanese Dermatological Association committee (2015 and 2020) is also based on the aforementioned diagnostic criteria [1]. AD has chronic and relapsing characteristics. Hence, AD (the outcome of interest) was defined as at least three records of ICD-9CM codes 691 (atopic dermatitis and related conditions) or 691.8 (other atopic dermatitis and related conditions) made by dermatologists or pediatricians in any diagnostic field during the inpatient or ambulatory claim process. All participants were followed up from baseline until the diagnosis of $\mathrm{AD}$, withdrawal from the NHI, or December 31, 2012. The mean follow-up duration in AD patients was 6.50 years (standard deviation [SD]: 3.39 years). The confounding factors included age, sex, level of urbanization, and monthly income. The level of urbanization was defined based on the population density and was graded into four levels. Urbanization level was defined according to a National Health Research Institutes report [21]. City districts and townships where the subjects were registered for insurance purposes were grouped into seven urbanization levels based on population density (population $/ \mathrm{km}^{2}$ ). Levels 1 and 7 referred to the most and the least urbanized areas, respectively. However, since very few patients were included in levels 5,6 , and 7; these three levels were combined with level 4. Monthly income was also classified into four groups: $<$ 14,400 New Taiwan dollar (NT\$); 14,400-18,300 NT\$; 18,301-21,000 NT\$; and $\geq 21,000$ NT\$.

\section{Exposure measurement}

The Taiwan Air Quality Monitoring Network was established by the Taiwan Environmental Protection Administration (TEPA) in 1993 [23, 24]. It comprises of 74 monitoring stations around the island. The monitoring stations are fully automated and record daily readings of THCs, NMHCs, and $\mathrm{CH}_{4}$ using ultraviolet fluorescence. Air pollution data were extracted from all monitoring stations and averaged on each day. The databases of these air pollutants were obtained from the Taiwan Air Quality-Monitoring Database (TAQMD), released by the TEPA. We linked the NHIRD and the TAQMD data according to the residential areas of candidates and the location of air quality-monitoring stations. A residential area was defined based on the location of the clinic and the hospital that treated acute nasopharyngitis (common cold) (ICD-9-CM code 460). Since acute nasopharyngitis is a common health problem, patients tend to visit the local clinic or other medical institution nearest to their residential areas. The average daily concentrations of air pollutants were calculated by dividing the cumulative daily air pollutant concentration by the duration from enrolment in this study to the endpoint for each candidate. Air pollutant concentrations were categorized into four groups based on quartiles: Q1, Q2, Q3, and Q4. THC concentrations were categorized into Q1 $(<2.29$ ppm), Q2 (2.29-2.40 ppm), Q3 (2.40-2.60 ppm), and Q4 $(>2.60 \mathrm{ppm})$. NMHC concentrations were categorized into Q1 $(<0.27 \mathrm{ppm}), \mathrm{Q} 2(0.27-0.35 \mathrm{ppm}), \mathrm{Q} 3(0.35-$ $0.51 \mathrm{ppm})$, and $\mathrm{Q} 4(>0.51 \mathrm{ppm}) \cdot \mathrm{CH}_{4}$ concentrations were categorized into Q1 $(<2.01 \mathrm{ppm}), \mathrm{Q} 2(2.01-2.06$ ppm), Q3 (2.06-2.11 ppm), and Q4 (> $2.11 \mathrm{ppm})$.

\section{Statistical analysis}

The demographic data in our study included age, sex, monthly income, level of residential urbanization, and daily average exposure to air pollutants. The chi-squared test was used to analyze the distributed difference among daily average concentrations for each air pollutant by quartile and urbanization. We used person-years as the denominator for estimating the incidence rate. The incidence rate of $\mathrm{AD}$ (per 1000 person-years) was calculated at four different air pollutant concentration levels. Cox proportional hazards regression models were applied to estimate the hazard ratios (HRs) and 95\% confidence intervals (CIs) for AD in Q2-Q4 levels of air pollutant concentrations when compared with the Q1 concentrations. The multivariable model was adjusted for age, sex, monthly income, and urbanization level. We also utilized the Kaplan-Meier method to estimate the cumulative incidence of $\mathrm{AD}$ during the follow-up. The log-rank test was used to analyze the difference among air pollutant concentration levels. All data analyses were performed using SAS 9.3 (SAS Institute Inc., Cary, NC, USA) and SPSS 15.1 (SPSS Inc., Chicago, IL, USA). The significance level was set at $p<0.05$ in all statistical tests.

\section{Results}

Altogether, 7304 children (2.96\%) were diagnosed with AD within the cohort of 246,844 children (between January 1, 2001 and December 31, 2012). The demographic data of the patients are presented in Table 1. The mean age of the patients was 6.50 years (SD: 3.39 years). The proportion of boys and girls was similar (51.6\% vs. $48.4 \%)$. Most of the participants were from families belonging to the lowest monthly income category $(83.4 \%)$ and resided in the most urbanized areas (33.2\%).

We collected the data of participants under conditions of $\mathrm{THC}, \mathrm{NMHC}$, and $\mathrm{CH}_{4}$ exposure based on the location of the Taiwan Air Quality Monitoring station. Concentrations of each air pollutant were categorized by quartiles, ranging from Q1 (the lowest concentration) to Q4 (the highest concentration). Tables 2, 3 and 4 show 
Table 1 The demographic information of study population

\begin{tabular}{|c|c|c|c|}
\hline$N=246,844$ & & $\mathrm{n}$ & $\%$ \\
\hline Gender & Boys & 126,256 & 51.6 \\
\hline \multirow[t]{4}{*}{ Age, years } & mean, SD & 6.50 & 3.39 \\
\hline & $\leqq 6$ & 126,967 & 51.4 \\
\hline & $7-12$ & 101,653 & 41.2 \\
\hline & $>12$ & 18,224 & 7.38 \\
\hline \multirow[t]{3}{*}{ Monthly income (NTD) ${ }^{a}$} & $<15,000$ & 205,871 & 83.4 \\
\hline & $15,000-19,999$ & 30,871 & 12.5 \\
\hline & $\geq 20,000$ & 10,102 & 4.09 \\
\hline \multirow[t]{4}{*}{ Urbanization level ${ }^{b}$} & 1 (highest) & 81,827 & 33.2 \\
\hline & 2 & 79,185 & 32.1 \\
\hline & 3 & 47,013 & 19.1 \\
\hline & 4 (lowest) & 38,819 & 15.7 \\
\hline \multicolumn{4}{|l|}{ Exposure } \\
\hline THC level (daily average) & mean, SD & 2.43 & 0.23 \\
\hline NMHC level (daily average) & mean, SD & 0.40 & 0.17 \\
\hline $\mathrm{CH}_{4}$ level (daily average) & mean, SD & 2.03 & 0.13 \\
\hline Follow years & mean, SD & 10.6 & 3.02 \\
\hline \multicolumn{4}{|l|}{ Outcome } \\
\hline Atopic dermatitis & & 7304 & 2.96 \\
\hline \multicolumn{4}{|c|}{$\begin{array}{l}\text { SD standard deviation } \\
\text { a Monthly income, New Taiwan Dollar (NTD), } 1 \text { NTD is equal to } 0.03 \text { USD } \\
\text { bUrbanization level: The urbanization level was categorized by the population } \\
\text { density of the residential area into } 4 \text { levels, with level } 1 \text { as the most urbanized } \\
\text { and level } 4 \text { as the least urbanized. THC total hydrocarbons, NMHCs non- } \\
\text { methane hydrocarbons, } \mathrm{CH}_{4} \text { methane }\end{array}$} \\
\hline
\end{tabular}

the baseline characteristics of children exposed to four levels of THC, $\mathrm{NMHC}$, and $\mathrm{CH}_{4}$ concentrations. Children with the highest $\mathrm{THC}$, $\mathrm{NMHC}$, and $\mathrm{CH}_{4}$ exposure concentrations lived in areas with higher urbanization.

Table 5 shows the increase in incidence rate of $\mathrm{AD}$ from 0.69 to 6.45 , from 1.72 to 4.37 , and from 0.73 to 7.74 per 1000 person-years with an increase in the THC, $\mathrm{NMHC}$, and $\mathrm{CH}_{4}$ exposure concentrations, respectively. In the multivariable Cox proportional hazard regression, the adjusted $\mathrm{HR}$ for $\mathrm{AD}$ increased with an increase in the $\mathrm{THC}, \mathrm{NMHC}$, and $\mathrm{CH}_{4}$ exposure concentrations from 1.65 (95\% CI: $1.47-1.84$ ) to 10.6 (95\% CI: $5.85-$ 7.07), from 1.14 (95\% CI: $1.06-1.24)$ to 2.47 (95\% CI: 2.29-2.66), and from 1.70 (95\% CI: $1.52-1.89$ ) to 11.9 (95\% CI: 10.8-13.1), respectively when compared with the corresponding exposure concentrations in the Q1 quartile (1.00) (Table 5).

Figure 1 shows the Kaplan-Meier curves for the cumulative incidence separated by pollutant concentrations in each quartile (Q1, Q2, Q3, and Q4). During a followup of 12 years, the cumulative incidence rates of $\mathrm{AD}$ were lower among children living in areas with lower quartile concentrations of THCs, NMHCs, and $\mathrm{CH}_{4}$ than among those living in areas with higher quartile concentrations.

\section{Discussion}

In the present population-based longitudinal study, we demonstrated that Taiwanese children exposed to higher

Table 2 Baseline characteristics of participants exposed to quartile (Q1-Q4) daily average concentrations of total hydrocarbons (THC)

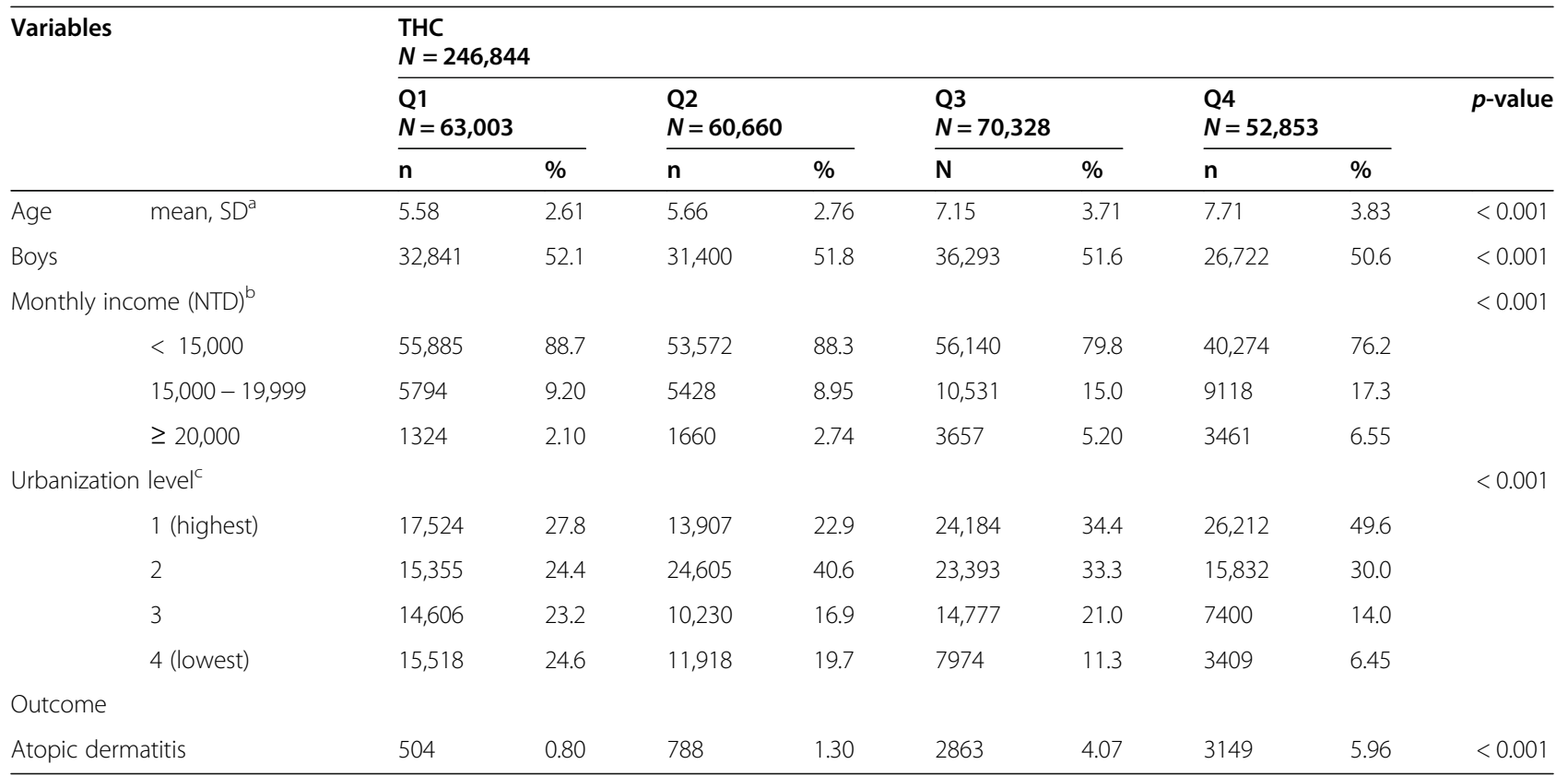

Chi-square test; ${ }^{a}$ One-way ANOVA; $S D$ standard deviation

${ }^{b}$ Monthly income: New Taiwan Dollar (NTD), 1 NTD is equal to 0.03 USD

'Urbanization level: The urbanization level was categorized by the population density of the residential area into 4 levels, with level 1 as the most urbanized and level 4 as the least urbanized 
Table 4 Baseline characteristics of participants exposed to quartile (Q1-Q4) daily average concentrations of methane $\left(\mathrm{CH}_{4}\right)$

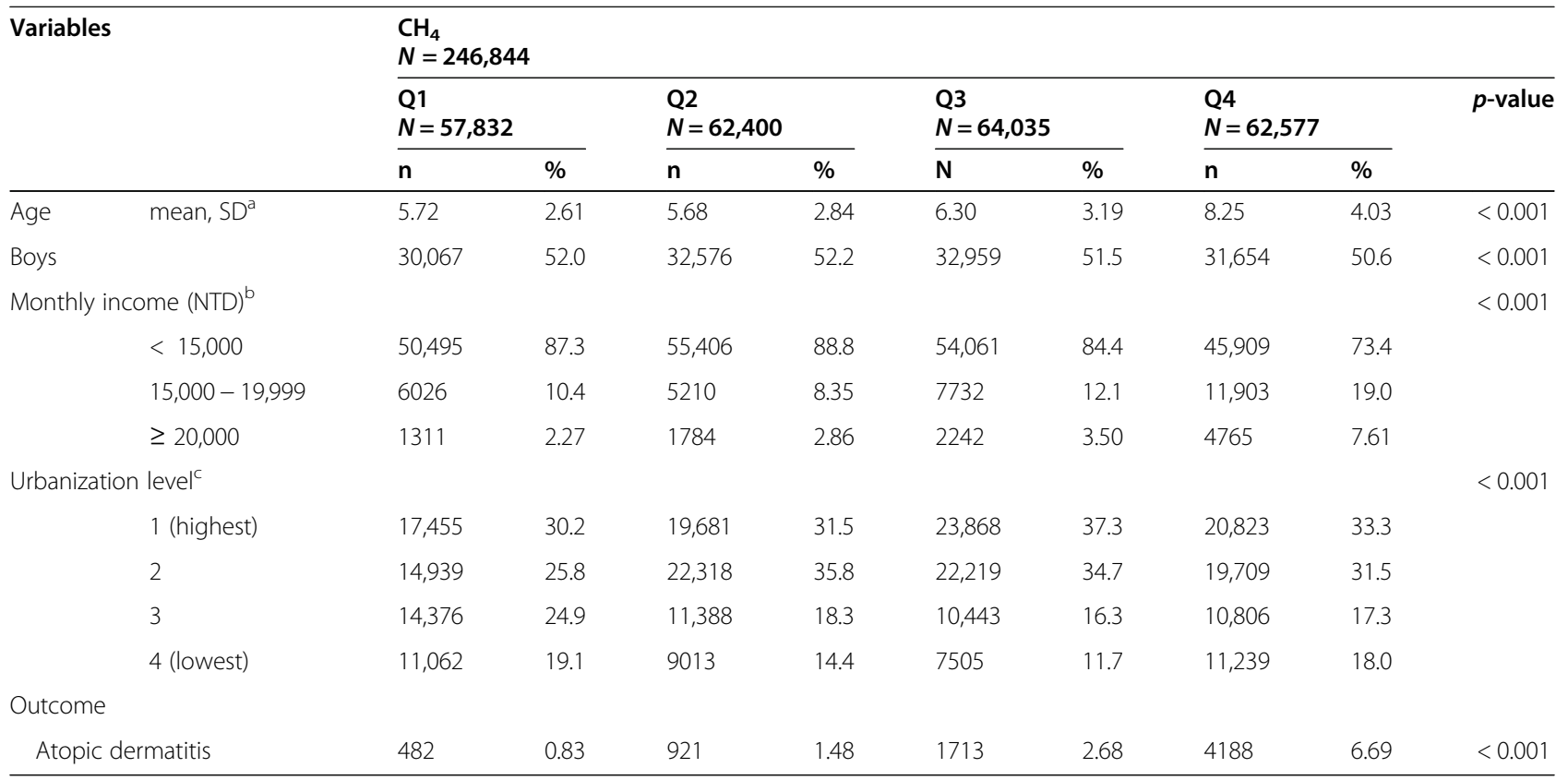

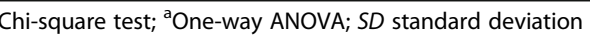

bonthly income: New Taiwan Dollar (NTD), 1 NTD is equal to 0.03 USD

'Urbanization level: The urbanization level was categorized by the population density of the residential area into 4 levels, with level 1 as the most urbanized and level 4 as the least urbanized

Table 3 Baseline characteristics of participants exposed to quartile (Q1-Q4) daily average concentrations of non-methane hydrocarbons (NMHC)

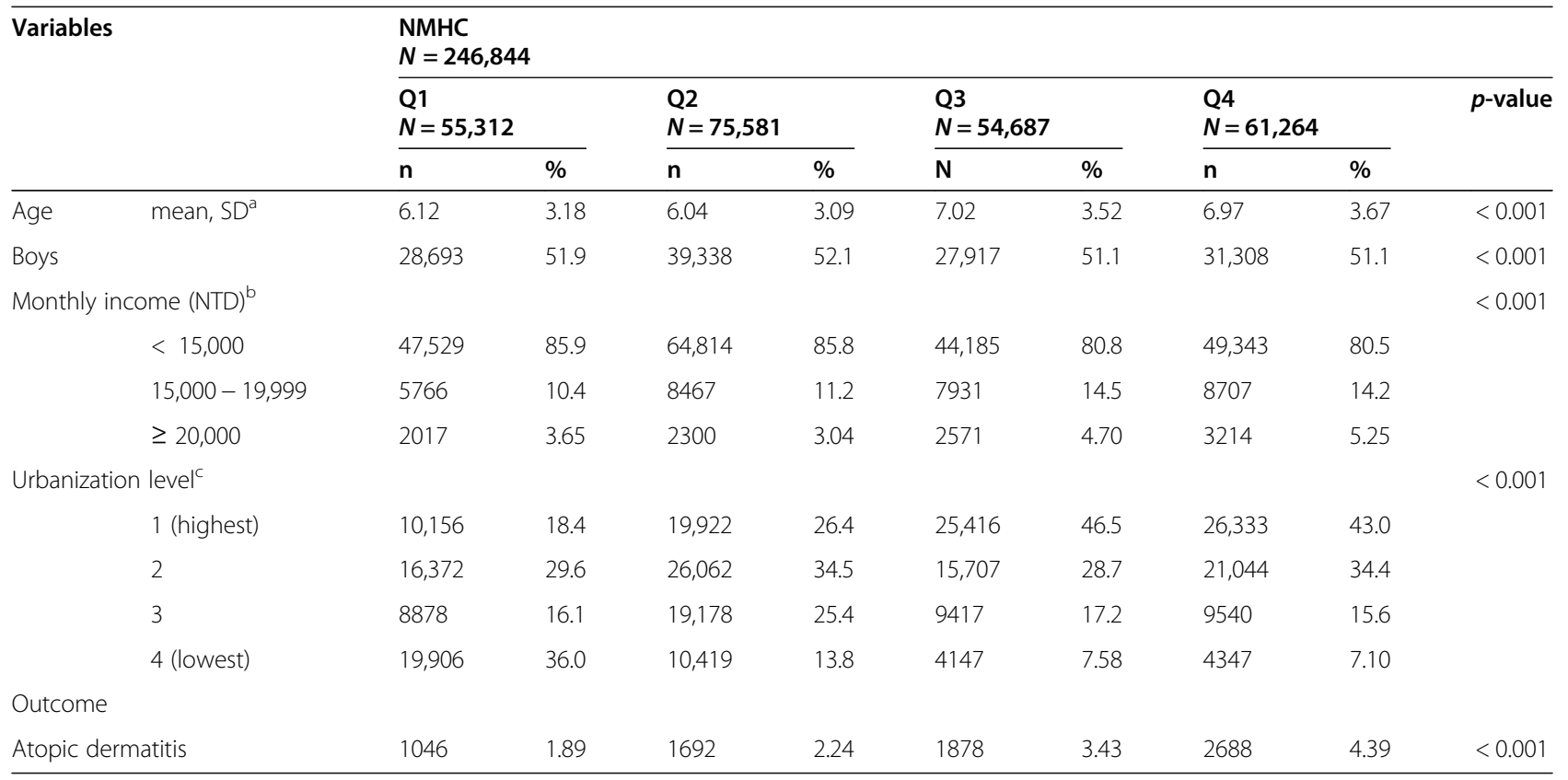

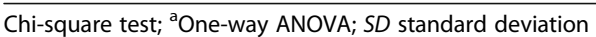

${ }^{\mathrm{b}}$ Monthly income: New Taiwan Dollar (NTD), 1 NTD is equal to 0.03 USD

'Urbanization level: The urbanization level was categorized by the population density of the residential area into 4 levels, with level 1 as the most urbanized and level 4 as the least urbanized 
Table 5 Comparisons of differences in atopic dermatitis incidences and associated HRs in participants exposed to quartile (Q1-Q4) daily average concentrations of air pollutants

\begin{tabular}{cllllllll}
\hline & Pollutant levels & Event & PY & IR & cHR & $\mathbf{9 5 \% C l}$ & aHR & 95\%Cl \\
\hline THC & & & & & & & & \\
Q1 & 63,003 & 504 & 729,958 & 0.69 & Ref. & & Ref. & \\
Q2 & 60,660 & 788 & 694,338 & 1.13 & 1.64 & $(1.47,1.83)$ & 1.65 & $(1.47,1.84)$ \\
Q3 & 70,328 & 2863 & 695,742 & 4.12 & 5.72 & $(5.21,6.29)$ & 6.43 & $(5.85,7.07)$ \\
Q4 & 52,853 & 3149 & 487,850 & 6.45 & 8.82 & $(8.03,9.69)$ & 10.6 & $(9.60,11.6)$ \\
NMHC & & & & & & & \\
Q1 & 55,312 & 1046 & 606,958 & 1.72 & Ref. & & Ref. & \\
Q2 & 75,581 & 1692 & 834,767 & 2.03 & 1.18 & $(1.09,1.27)$ & 1.14 & $(1.06,1.24)$ \\
Q3 & 54,687 & 1878 & 551,734 & 3.40 & 1.92 & $(1.78,2.07)$ & 1.93 & $(1.79,2.09)$ \\
Q4 & 61,264 & 2688 & 614,430 & 4.37 & 2.48 & $(2.31,2.66)$ & 2.47 & $(2.29,2.66)$ \\
CH4 & & & & & & & \\
Q1 & 57,832 & 482 & 664,004 & 0.73 & Ref. & & Ref. & \\
Q2 & 62,400 & 921 & 713,125 & 1.29 & 1.79 & $(1.60,1.99)$ & 1.70 & $(1.52,1.89)$ \\
Q3 & 64,035 & 1713 & 689,674 & 2.48 & 3.38 & $(3.05,3.73)$ & 3.32 & $(3.00,3.67)$ \\
Q4 & 62,577 & 4188 & 541,086 & 7.74 & 9.99 & $(9.09,11.0)$ & 11.9 & $(10.8,13.1)$ \\
\hline
\end{tabular}

PY person-years

IR Incidence rate, (per 1000 person-years)

$c H R$ crude hazard ratio

$a H R$ adjusted hazard ratio of a multivariate analysis, after adjustment for age, sex, monthly income, and urbanization level

$\mathrm{Cl}$ vconfidence interval

Ref. reference group

THC total hydrocarbons, NMHCs non-methane hydrocarbons, $\mathrm{CH}_{4}$ methane

concentrations of THCs, NMHCs, and $\mathrm{CH}_{4}$ were at an increased risk of developing $\mathrm{AD}$ regardless of adjustment for potential confounding factors such as age, sex, monthly income, and urbanization level. Our cohort study also revealed a clear dose-response relationship between air pollution and AD. The present study is distinctive in several respects. We assessed the real-world data from the Children's File. Children are more susceptible than adults to the effects of air pollution, as their lungs and immune systems are still developing, they breathe faster than adults, and their respiratory tracts are more permeable [25]. AD diagnosis in our study was confirmed by a physician, minimizing the potential for selection bias. Our study might be one of the first to

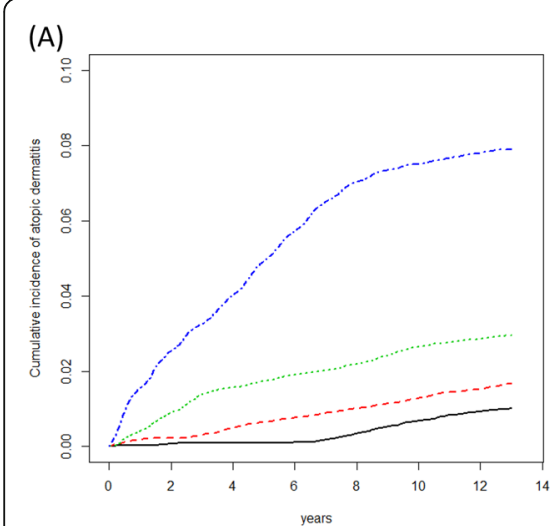

(B)

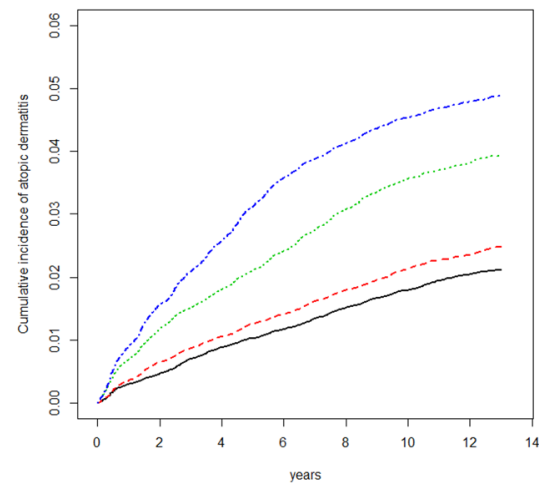

(C)

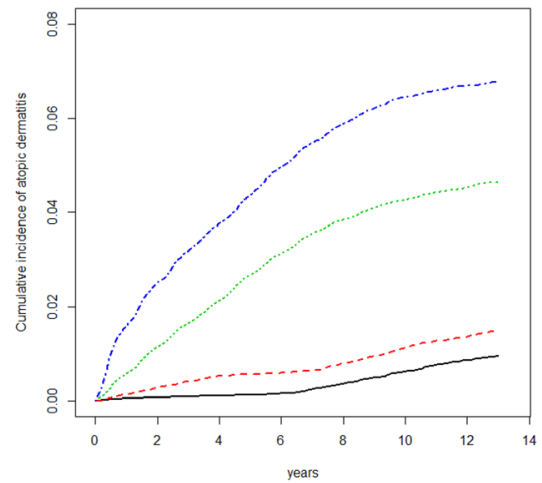

Fig. 1 The cumulative incidence of atopic dermatitis in participants exposed to quartile daily average quartile concentrations of (A) total hydrocarbon (THC), (B) non-methane hydrocarbons (NMHC), and $(\mathbf{C})$ methane (CH4). First quartile (solid line), first quartile to second quartile (dashed line), second quartile to third quartile (dotted line), $\geqq$ third quartile concentration (dot dash line) 
investigate the relationship between $\mathrm{AD}$ and $\mathrm{CH}_{4}$, an active greenhouse gas, to identify the dermatological effect of a single component.

Taiwan is located in East Asia, the most polluted region in the world. Currently, it is facing severe air pollution, especially in major urban areas, due to rapid increase in population and industrial development as well as transportation demands. While the number of children with AD continues to increase in both developed and developing countries, the prevalence of $\mathrm{AD}$ in Taiwan appears to have grown dramatically over recent decades [26]. According to the Taiwan National Study 2000 to 2007, the overall 8-year prevalence of AD is approximately $6.7 \%$ [27]. Due to such rapid growth in the number of $\mathrm{AD}$ cases with increased urbanization and industrialization, the role of environmental factors, especially airborne pollutants, has garnered increasing attention. Over the past 10 years, a number of studies have shown that TRAP and air pollutants such as PM, VOCs, and ETS are associated with the development and exacerbation of AD. Multiple comprehensive studies have been conducted in pediatric age group with a large dataset. In a French study that enrolled 4907 children who had resided at their current addresses for 3 years or longer, lifetime $\mathrm{AD}$ was significantly associated with 3-year averaged concentrations of $\mathrm{PM}_{10}, \mathrm{NO}_{2}, \mathrm{NO}_{\mathrm{x}}$, and $\mathrm{CO}$ (adjusted odds ratios [ORs]: 1.13, 1.23, 1.06, and 1.08, respectively) [28]. In a prospective birth cohort study from Munich that included 2860 children aged 4 years, $\mathrm{NO}_{2}$ exposure (per $6.4 \mathrm{mg} / \mathrm{m}^{3}$ ) was associated with both physician-diagnosed $\mathrm{AD}$ and parental reports of $\mathrm{AD}$ symptoms (ORs: 1.18 and 1.11, respectively) [29]. In a cross-sectional study from Shanghai during 2011-2012 that enrolled 3358 preschool children, a positive correlation was observed between increased gestational and lifetime exposure to a mixture of $\mathrm{SO}_{2}, \mathrm{NO}_{2}$, and $\mathrm{PM}_{10}$ and childhood AD (ORs: 1.78 and 1.87, respectively) [30]. In 91,642 children from the US National Survey of Children's Health, moderate to severe eczema was associated with elevated levels of $\mathrm{NO}_{3}$ and $\mathrm{PM}_{2.5}$ (ORs: 1.249 and 1.070, respectively) [31]. A few studies also revealed that prenatal exposure to VOCs and ETS are likely to induce a Th2-dominant immune status or the development of AD after birth [32-34]. In the present study, we observed that the adjusted HRs for $\mathrm{AD}$ increased with an increase in the exposure concentration of THCs (from 1.65 to 10.6), NMHCs (from 1.14 to 2.47), and $\mathrm{CH}_{4}$ (from 1.70 to 11.9) when compared with exposure to the corresponding concentrations in the Q1 quartile.

Rapid industrialization coupled with urbanization has led to accumulated global waste production due to the continuously increasing demand for energy. Hydrocarbons, which are organic chemical compounds consisting of hydrogen and carbon, form the basis of the majority of global energy production via fossil fuel combustion and evaporation of gasoline. Both $\mathrm{NMHCs}$ and $\mathrm{CH}_{4}$ are composed of THCs. Most of the hydrocarbons on earth are naturally derived from decomposition of organic matter in petroleum and are generated by human activity. NMHCs, often referred to as VOCs, are unstable forms of substances such as benzene and their derivatives.

A great number of animal and epidemiological studies have reported negative effects of VOCs on skin barrier function. A prospective study in Korea revealed that an increase of $1 \mathrm{ppb}$ in outdoor benzene and total VOC concentrations was associated with a 27.38 and $25.86 \%$ increase in AD symptoms, respectively [14]. Kim et al. observed that exposure to airborne formaldehyde leads to an increase in transepidermal water loss and stratum corneum $\mathrm{pH}$ in healthy subjects as well as in $\mathrm{AD}$ patients [15]. In a rat AD model, Han et al. showed that formaldehyde exposure aggravated pruritus and skin inflammation. These results suggest that formaldehyde penetrated the injured skin barrier and exacerbated Th1 responses and serum IgE levels in $\mathrm{AD}$ rats [35]. In several previous studies, certain VOCs and polycyclic aromatic hydrocarbons have been proposed to activate the ligand-activated transcription factor AhR, leading to downstream activation of inflammation and itch mediators such as artemin [36, 37]. Adverse health effects of direct exposure to $\mathrm{CH}_{4}$, a nontoxic greenhouse gas, have been scarcely reported except suffocation due to high concentrations. The present study is the first one to suggest that $\mathrm{CH}_{4}$ exposure contributes to an increased risk of $\mathrm{AD}$ development. Rapid industrialization and urbanization contribute to increased $\mathrm{CH}_{4}$ production. Increasing urbanization has been accompanied by a rise in larger cities with increasing population densities. Densely populated areas aggravate the spread of contagious infectious diseases. Emerging infectious diseases may worse skin inflammation caused by AD [38]. Further studies are needed to confirm this hypothesis.

Although our study was a large-scale population-based cohort study, it has several limitations. Although AD is a complex and multifactorial disorder, we did not consider other environmental factors such as temperature, humidity, and ultraviolet light that might interact with airborne pollutants [39]. Other potential risk factors for $\mathrm{AD}$ such as atopic family history, dietary factors, pet and prenatal exposure, and even the severity of AD could not be estimated in the present study due to the lack of information in the Children's File. The reported prevalence of $\mathrm{AD}$ was $7.2 \%$ in a previous study wherein 11,874 students from 14 schools in central Taiwan completed the International Study of Asthma and Allergies in Childhood questionnaire [40]. However, the present study revealed a prevalence of $2.96 \%$ during the study 
period. This finding implies that $\mathrm{AD}$ might have been underdiagnosed in the present study, particularly in those with mild or infrequent symptoms. This disparity in findings might be explained by the following factors. We defined $\mathrm{AD}$ as at least three medical records of ICD9-CM codes 691 or 691.8 due to the chronic and relapsing nature of $\mathrm{AD}$ and to avoid overdiagnosis. Thus, although this approach reduced the risk of false positives, it might have led to a low prevalence of AD diagnosis during the study period. Patients with mild AD may not seek medical services or be coded for the clinical diagnosis of AD by a physician. Moreover, the selection of another ICD-9-CM code for the diagnosis of $\mathrm{AD}$ by a physician may also lead to underestimation of AD prevalence. Furthermore, due to the inclusion characteristics of our database, children enrolled during the study period who became older than 18 years of age in 2012 were also taken into account. Thus, the exposure measurement might have been calculated partially after the age of 18. Exposure to indoor air pollution was not investigated in our study. Hence, our results might not represent the overall effect of air pollution on AD [41].

\section{Conclusion}

Our findings indicated that exposure to higher concentrations of THCs, NMHCs, and $\mathrm{CH}_{4}$ might lead to an increased risk of $\mathrm{AD}$ development. Further studies are needed to gain a better understanding of the role of air pollutants in the pathogenesis of $\mathrm{AD}$.

\section{Abbreviations}

AD: Atopic dermatitis; $\mathrm{CH}_{4}$ : Methane; $\mathrm{Cl}$ : Confidence interval;

ETS: Environmental tobacco smoke; HR: Hazard ratio; ICD-9-CM: International Classification of Disease, 9th Revision, Clinical Modification; NHI: National Health Insurance; NHIRD: National Health Insurance Research Database; NMHCs: Non-methane hydrocarbons; $\mathrm{NO}_{x}$ : Nitrogen oxide compounds; NT\$: New Taiwan dollar; OR: Odds ratio; PM: Particulate matter; SD: Standard deviation; TAQMD: Taiwan Air Quality-Monitoring Database; TEPA: Taiwan Environmental Protection Administration; THCs: Total hydrocarbons; TRAP: Traffic-related air pollution; VOC: Volatile organic compound

\section{Financial disclosure}

The authors have indicated they have no financial relationships relevant to this article to disclose.

\section{Data sharing statement}

No additional data.

\section{Authors' contributions}

Chang-Ching Wei conceptualized and designed the study. Chieh Wang and Jeng-Dau Tsai drafted the initial manuscript. Cheng-Li Lin carried out the acquisition of data and analysis and interpretation of data. Lei Wan and critically reviewed and revised the manuscript. Chang-Ching Wei and Jeng-Dau Tsai coordinated and supervised data collection, critically reviewed the manuscript, and approved the final manuscript as submitted.

\section{Funding}

This study is supported in part by Clinical Trial Center and Department of Chinese Medicine and Pharmacy, Ministry of Health and Welfare (MOHW109TDU-B-212-114004), China Medical University Hospital (CRS-108-015, DMRHHC-109-9, and DMR-HHC-110-7).
Availability of data and materials

Data available on request due to privacy/ethical restrictions.

\section{Declarations}

\section{Ethics approval and consent to participate}

The data were analyzed anonymously and informed consent is not applicable. This study has been approved by the Institute Review Board of China Medical University Hospital (CRREC-103-048) and complies with the principles outlined in the Helsinki Declaration.

\section{Consent for publication}

This manuscript is an original article that has not been previously published and will not be submitted to any other journal. All the authors have read this manuscript and agree that the work is ready for submission, and accept responsibility for the manuscript's contents.

\section{Competing interests}

None.

\section{Author details}

'Department of Chinese Medicine, China Medical University Hospital, Taichung, Taiwan. ${ }^{2}$ Children's Hospital, China Medical University Hospital, Taichung, Taiwan. ${ }^{3}$ School of Medicine, China Medical University, Taichung, Taiwan. ${ }^{4}$ School of Chinese Medicine, China Medical University, Taichung, Taiwan. ${ }^{5}$ Management Office for Health Data, China Medical University Hospital, Taichung, Taiwan. ${ }^{6}$ Institute of Biostatistics, China Medical University, Taichung, Taiwan. ${ }^{7}$ School of Medicine, Chung Shan Medical University, Taichung, Taiwan. ${ }^{8}$ Department of Pediatrics, Chung Shan Medical University Hospital, Taichung, Taiwan.

Received: 12 October 2020 Accepted: 20 September 2021

Published online: 09 October 2021

\section{References}

1. Chan TC, Wu NL, Wong LS, Cho YT, Yang CY, Yu Y, et al. Taiwanese dermatological association consensus for the management of atopic dermatitis: a 2020 update. J Formos Med Assoc. 2021;120(1 Pt 2):429-42 https://doi.org/10.1016/j.jfma.2020.06.008.

2. Rudzki E, Samochocki Z, Rebandel P, Saciuk E, Gałecki W, Rączka A, et al. Frequency and significance of the major and minor features of Hanifin and Rajka among patients with atopic dermatitis. Dermatology. 1994;189(1):41-6. https://doi.org/10.1159/000246781

3. Spergel JM, Paller AS. Atopic dermatitis and the atopic march. J Allergy Clin Immunol. 2003;112(6 Suppl):S118-27. https:/doi.org/10.1016/j.jaci.2003.09.033.

4. Mastrorilli C, Caffarelli C, Hoffmann-Sommergruber K. Food allergy and atopic dermatitis: prediction, progression, and prevention. Pediatr Allergy Immunol. 2017;28(8):831-40. https://doi.org/10.1111/pai.12831.

5. Eichenfield LF, Hanifin JM, Beck LA, Lemanske RF Jr, Sampson HA, Weiss ST, et al. Atopic dermatitis and asthma: parallels in the evolution of treatment. Pediatrics. 2003;111(3):608-16. https://doi.org/10.1542/peds.111.3.608.

6. Bieber T. Atopic dermatitis. N Engl J Med. 2008;358(14):1483-94. https://doi. org/10.1056/NEJMra074081.

7. Margolis JS, Abuabara K, Bilker W, Hoffstad O, Margolis DJ. Persistence of mild to moderate atopic dermatitis. JAMA Dermatology. 2014;150(6):593600. https://doi.org/10.1001/jamadermatol.2013.10271.

8. Kim JP, Chao LX, Simpson EL, Silverberg Jl. Persistence of atopic dermatitis (AD): a systematic review and meta-analysis. J Am Acad Dermatol. 2016; 75(4):681-7. https://doi.org/10.1016/j.jaad.2016.05.028.

9. Drucker AM, Wang AR, Li WQ, Sevetson E, Block JK, Qureshi AA. The burden of atopic dermatitis: summary of a report for the National Eczema Association. J Invest Dermatol. 2017;137(1):26-30. https://doi.org/10.1016/j. jid.2016.07.012.

10. Bickers DR, Lim HW, Margolis D, Weinstock MA, Goodman C, Faulkner E, et al. The burden of skin diseases: 2004 a joint project of the American Academy of Dermatology Association and the Society for Investigative Dermatology. J Am Acad Dermatol. 2006;55(3):490-500. https://doi.org/10.1 016/j.jaad.2006.05.048

11. Ahn K. The role of air pollutants in atopic dermatitis. J Allergy Clin Immunol. 2014;134(5):993-9. https://doi.org/10.1016/j.jaci.2014.09.023. 
12. Lu C, Deng L, Ou C, Yuan H, Chen X, Deng Q. Preconceptional and perinatal exposure to traffic-related air pollution and eczema in preschool children. J Dermatol Sci. 2017;85(2):85-95. https://doi.org/10.1016/j.jdermsci.2016.11.004.

13. Deng Q, Lu C, Li Y, Sundell J, Dan N. Exposure to outdoor air pollution during trimesters of pregnancy and childhood asthma, allergic rhinitis, and eczema. Environ Res. 2016;150:119-27. https://doi.org/10.1016/j.envres.2016. 05.050.

14. Kim J, Kim EH, Oh I, Jung K, Han Y, Cheong HK, et al. Symptoms of atopic dermatitis are influenced by outdoor air pollution. J Allergy Clin Immunol. 2013;132(2):495-8 e491.

15. Kim J, Han Y, Ahn JH, Kim SW, Lee SI, Lee KH, et al. Airborne formaldehyde causes skin barrier dysfunction in atopic dermatitis. Br J Dermatol. 2016; 175(2):357-63. https://doi.org/10.1111/bjd.14357.

16. Hendricks AJ, Eichenfield LF, Shi VY. The impact of airborne pollution on atopic dermatitis: a literature review. Br J Dermatol. 2020;183(1):16-23. https://doi.org/10.1111/bjd.18781

17. Hassoun Y, James C, Bernstein DI. The effects of air pollution on the development of atopic disease. Clin Rev Allergy Immunol. 2019;57(3):40314. https://doi.org/10.1007/s12016-019-08730-3.

18. He QC, Tavakkol A, Wietecha K, Begum-Gafur R, Ansari SA, Polefka T. Effects of environmentally realistic levels of ozone on stratum corneum function. Int J Cosmet Sci. 2006;28(5):349-57. https://doi.org/10.1111/j.1467-2494.2006. 00347.x.

19. Choi H, Shin DW, Kim W, Doh SJ, Lee SH, Noh M. Asian dust storm particles induce a broad toxicological transcriptional program in human epidermal keratinocytes. Toxicol Lett. 2011;200(1-2):92-9. https://doi.org/10.1016/j. toxlet.2010.10.019.

20. Araviiskaia E, Berardesca E, Bieber T, Gontijo G, Sanchez Viera M, Marrot L, et al. The impact of airborne pollution on skin. J Eur Acad Dermatol Venereol. 2019;33(8):1496-505. https://doi.org/10.1111/jdv.15583.

21. National Health Insurance Administration Ministry of Health and Welfare. http://www.nhi.gov.tw/English/. Accessed 31 Mar 2021.

22. Chang LC, Huang N, Chou YJ, Lee CH, Kao FY, Huang YT. Utilization patterns of Chinese medicine and Western medicine under the National Health Insurance Program in Taiwan, a population-based study from 1997 to 2003. BMC Health Serv Res. 2008;8(1):170. https://doi.org/10.1186/1472-6963-8-170.

23. Taiwan Air Quality Monitoring Network. Environmental Protection Administration Executive Yuan, R.O.C. (Taiwan). https://airtw.epa.gov.tw/ ENG/default.aspx. Accessed 31 Mar 2021.

24. Environmental Resource Database. Environmental Protection Administration Executive Yuan, R.O.C. (Taiwan). https://www.epa.gov.tw/ENG/. Accessed 31 Mar 2021.

25. Salvi S. Health effects of ambient air pollution in children. Paediatr Respir Rev. 2007;8(4):275-80. https://doi.org/10.1016/j.prrv.2007.08.008.

26. Lee YL, Li CW, Sung FC, Yu HS, Sheu HM, Guo YL. Environmental factors, parental atopy and atopic eczema in primary-school children: a crosssectional study in Taiwan. Br J Dermatol. 2007;157(6):1217-24. https://doi. org/10.1111/j.1365-2133.2007.08215.x.

27. Hwang CY, Chen YJ, Lin MW, Chen TJ, Chu SY, Chen CC, et al. Prevalence of atopic dermatitis, allergic rhinitis and asthma in Taiwan: a national study 2000 to 2007. Acta Derm Venereol. 2010;90(6):589-94. https://doi.org/10.234 0/00015555-0963.

28. Pénard-Morand C, Raherison C, Charpin D, Kopferschmitt C, Lavaud F, Caillaud $\mathrm{D}$, et al. Long-term exposure to close-proximity air pollution and asthma and allergies in urban children. Eur Respir J. 2010;36(1):33-40. https://doi.org/10.1183/09031936.00116109.

29. Morgenstern V, Zutavern A, Cyrys J, Brockow I, Koletzko S, Krämer U, et al. Atopic diseases, allergic sensitization, and exposure to traffic-related air pollution in children. Am J Respir Crit Care Med. 2008;177(12):1331-7. https://doi.org/10.1164/rccm.200701-0360C

30. Liu W, Cai J, Huang C, Hu Y, Fu Q, Zou Z, et al. Associations of gestational and early life exposures to ambient air pollution with childhood atopic eczema in Shanghai, China. Sci Total Environ. 2016;572:34-42. https://doi. org/10.1016/j.scitotenv.2016.07.197.

31. Kathuria P, Silverberg Jl. Association of pollution and climate with atopic eczema in US children. Pediatr Allergy Immunol. 2016;27(5):478-85. https:// doi.org/10.1111/pai.12543.

32. Herberth G, Bauer M, Gasch M, Hinz D, Röder S, Olek S, et al. Maternal and cord blood miR-223 expression associates with prenatal tobacco smoke exposure and low regulatory T-cell numbers. J Allergy Clin Immunol. 2014; 133(2):543-50. https://doi.org/10.1016/j.jaci.2013.06.036.
33. Hinz D, Bauer M, Röder S, Olek S, Huehn J, Sack U, et al. Cord blood Tregs with stable FOXP3 expression are influenced by prenatal environment and associated with atopic dermatitis at the age of one year. Allergy. 2012;67(3): 380-9. https://doi.org/10.1111/j.1398-9995.2011.02767.x.

34. Lehmann I, Thoelke A, Rehwagen M, Rolle-Kampczyk U, Schlink U, Schulz R, et al. The influence of maternal exposure to volatile organic compounds on the cytokine secretion profile of neonatal T cells. Environ Toxicol. 2002;17(3): 203-10. https://doi.org/10.1002/tox.10055.

35. Han RT, Back SK, Lee H, Lee J, Kim HY, Kim HJ, et al. Formaldehyde-induced aggravation of pruritus and dermatitis is associated with the elevated expression of Th1 cytokines in a rat model of atopic dermatitis. PLoS One. 2016;11(12):e0168466. https://doi.org/10.1371/journal.pone.0168466.

36. Mancebo SE, Wang SQ. Recognizing the impact of ambient air pollution on skin health. J Eur Acad Dermatol Venereol. 2015;29(12):2326-32. https://doi. org/10.1111/jdv.13250

37. Hidaka T, Ogawa E, Kobayashi EH, Suzuki T, Funayama R, Nagashima T, et al. The aryl hydrocarbon receptor AhR links atopic dermatitis and air pollution via induction of the neurotrophic factor artemin. Nat Immunol. 2017;18(1): 64-73. https://doi.org/10.1038/ni.3614.

38. Neiderud CJ. How urbanization affects the epidemiology of emerging infectious diseases. Infect Ecol Epidemiol. 2015;5(1):27060. https://doi.org/1 0.3402/iee.v5.27060

39. Patella V, Florio G, Palmieri M, Bousquet J, Tonacci A, Giuliano A, et al. Atopic dermatitis severity during exposure to air pollutants and weather changes with an artificial neural network (ANN) analysis. Pediatr Allergy Immunol. 2020;31(8):938-45. https://doi.org/10.1111/pai.13314.

40. Liao MF, Huang JL, Chiang LC, Wang FY, Chen CY. Prevalence of asthma, rhinitis, and eczema from ISAAC survey of schoolchildren in Central Taiwan. J Asthma. 2005;42(10):833-7. https://doi.org/10.1080/02770900500369892.

41. Breysse PN, Diette GB, Matsui EC, Butz AM, Hansel NN, McCormack MC. Indoor air pollution and asthma in children. Proc Am Thorac Soc. 2010;7(2): 102-6. https://doi.org/10.1513/pats.200908-083RM.

\section{Publisher's Note}

Springer Nature remains neutral with regard to jurisdictional claims in published maps and institutional affiliations.
Ready to submit your research? Choose BMC and benefit from:

- fast, convenient online submission

- thorough peer review by experienced researchers in your field

- rapid publication on acceptance

- support for research data, including large and complex data types

- gold Open Access which fosters wider collaboration and increased citations

- maximum visibility for your research: over $100 \mathrm{M}$ website views per year

At $\mathrm{BMC}$, research is always in progress.

Learn more biomedcentral.com/submissions 